ovulatory cycles with good sperm tolerance. The tests were performed from 10 to 18 days after the last additional oestrogen tablet was taken.

\section{Discussion}

The incidence of uterine bleeding and menstrual cycle modifications in women receiving oral continuous chlormadinone acetate in microdoses is significant. In our experience 153 $(39.2 \%)$ out of 390 women presented some alterations in uterine bleeding while using this contraceptive method; amenorrhoea, for instance, was observed in $15 \%$ of our subjects. However, the modifications of menstrual cycles were slightly less frequent (in $147(37.6 \%)$ out of 390 treated subjects). The most annoying symptoms indeed were amenorrhoea, protonged cycles, and intermenstrual bleeding.

These alterations are apparently related to the antioestrogenic effect of the progestogen and are shown by those subjects more sensitive to such action. Furthermore, our macroscopic and microscopical observations on ovaries of subjects treated with $0.5 \mathrm{mg}$. of chlormadinone daily, who presented prolonged menstrual cycles or amenorrhoea, showed that ovulation was inhibited. A marked effect of the compound at the endometrium stroma and glands was also evident (Zañartu et al., 1967b).

These findings help us to understand why additional ostrogen therapy given for a few days for bleeding and cycle regulation could eventually reverse the effect in cervical mucus of chlormadinone $0.5 \mathrm{mg}$. daily, and yet preserve the main contraceptive effect of the therapy at other levels of the reproductive system (endometrium, endosalpinx).

The gratifying action of the accessory oestrogens by correcting uterine bleeding and regulating cycles significantly helps to improve the acceptability of this valuable contraceptive method. It has also been valuable in improving the acceptability of other progestogens in microdosage.

\section{Summary}

Fifty women presenting alterations of uterine bleeding and menstrual cycles while using oral continuous $0.5-\mathrm{mg}$. chlormadinone tablets for fertility control were given additional oral oestrogens to correct the condition. Conjugated oestrogens 2.5- or 5-mg. tablets were given for five to seven days in each calendar month. Ethinyloestradiol $0.05 \mathrm{mg}$. was also used when well tolerated. The continuous oral administration of chlormadinone tablets was maintained.

Accessory oestrogens were useful in correcting the bleeding and cycle disturbances resulting from the anti-oestrogenic effect of microdoses of oral chlormadinone without interfering with the fertility inhibition effect. It is suggested that the addition of oral oestrogens is useful to improve acceptability of continuous chlormadinone in microdoses as a contraceptive while maintaining the outstanding properties of this therapy.

Chlormadinone acetate $0.5-\mathrm{mg}$. tablets were generously donated by Syntex International (Mexico) and E. Merck-Darmstadt (Germany). We are indebted to Ayerst Laboratories Inc. (New York) for the supply of conjugated oestrogens (Premarin).

\section{REFERENCES}

Martinez-Manautou, J., Cortez, V., Giner-Velasquez, J., Aznar, R., Casasuia, J., and Rudel, H. W. (1966a). Fertil. and Steril., 17, 49.' Aznar, R., Lnzano-Balderas, M., and Rudel, H. W. (1967a). Report to Vill World Congress of the I.P.P.F. (Santiago, Chile), April.

Giner-Velasquez, J., Cortez-Gallegos, V., Casasola, J., Aznar, R., and Rudel. H. W. (1966b). Excerpta Medica International Congress

Series, No. 112, p. 157. Amsterdam. et al. (1967c). Brit. med. 3., 2, 730 . and Rudel, H. W. (1967). Excerpia Medica International Congress Series. In press.

Rudel, H. W., and Martinez-Manautou, J. (1966). Ibid., No. 111, p. 82. Amstcrdam.

Zañartu, J., Rodriguez-Moore, G., Pupkin, M., Salas, O., and Guerrero, R. (196,7a). Obstet. Ginec. lat.-amer. In press.

Rosenberg, D.. Pupkin, M., and Guerrero, R. (1967b). The Effect of Oral Continuous Chlormadinone Micro-doses in the Human Ovaries. To be published.

\title{
Transfer Factor (Diffusing Capacity) for the Lung in Simple Pneumoconiosis of Coal Workers
}

\author{
J. P. LYONS,* M.D. ; W. G. CLARKE, † M.S.R., A.R.P.S. ; A. M. HALL†; J. E. COTES, † D.M., M.R.C.P.
}

Brit. med. F., 1967, 4, 772-774

Established simple pneumoconiosis of coal workers is accompanied by a widening of the alveolar-arterial tension difference for oxygen (Brasseur, 1963) and a minimal reduction in the transfer factor (diffusing capacity) for the lung, measured by the steady state carbon monoxide method (Podlesch, Stevanowic, and Ulmer, 1966). These changes are probably due to uneven distribution of pulmonary ventilation and perfusion. The finding of a low transfer factor by this method is not necessarily evidence for a transfer defect ; this is better assessed by the single-breath carbon monoxide method, which is less susceptible to the effects of uneven distribution. With this method a number of workers have found a proportion of men with simple pneumoconiosis to have a transfer defect (for references see Nicaise, Vereerstraten, and de Clercq, 1967); the change may be accompanied by an increase in the quantity of reticulum in the lung parenchyma (Gaensler, Hoffman, and

- Pneumoconiosis Medical Panel, Cardiff.

t Pneumoconiosis Research Unit of the Medical Research Council, Llaniough Hospital, Penarth, Glamorgan.

Requests for reprints and for detalls of the physiological results should be addressed to Dr. Cotes.
Elliott, 1960). A weak association with the punctate or pinhead type of radiological opacities has been suggested by Englert and De Coster (1965). The present observations on men attending a pneumoconiosis medical panel appear to confirm this finding, which is also supported by recent work from Belgium (L. Billiet, personal communication to J. E. C.).

\section{Subjects and Methods}

Over a period of 16 months men attending the Pneumoconiosis Medical Panel, Cardiff, who were thought to have simple pneumoconiosis of a pin-head type (punctiform opacities up to $1.5 \mathrm{~mm}$. in diameter (International Labour Office, 1959)) together with some of a micronodular type (opacities of $1.5-3 \mathrm{~mm}$. in diameter) were referred to the Pneumoconiosis Research Unit for assessment. Here the chest radiographs were read in duplicate by an independent observer (W. G. C.) ; respiratory symptoms were assessed by use of the M.R.C. Respiratory Questionary (Medical Research Council, 1960); and measurements were made of ventilatory capacity, 
lung volumes, and transfer factor (single breath for carbon monoxide), standard methods being used (Cotes, 1965 ; Meade et al., 1965 ; International Labour Office, 1966). For each subject the findings on assessment of lung function were reported on at the time by one of us (J.E.C.) as being within the normal range or showing nonspecific changes, or as showing a ventilation defect of an obstructive type (low F.E.V.\%, high R.V./T.L.C. \%, and impaired mixing of inspired gas, but normal T.F. and T.L.C.), a transfer defect (low T.F. with normal or reduced T.L.C. and no evidence for airway obstruction), or possible emphysema (low F.E.V.\% and increased T.L.C. with or without a reduced transfer factor).

\section{Results}

Forty-seven subjects were thought to have simple pneumoconiosis involving all rib spaces in at least one lung (categories 2 and 3 of the International Labour Office classification). Of these men, on the basis of the first reading of the chest radiograph by W. G. C., 16 were thought to have only pin-head opacities, 11 only micronodular opacities, and 20 mixed opacities or additional lesions. The findings for the subjects classified in this way are summarized in Table I. The results of the lung function tests for the subjects who appeared to have simple pneumoconiosis of a pure pin-head or a pure micronodular type are reported in greater detail in Table II.

ТАВLВ I.-Summary of Findings

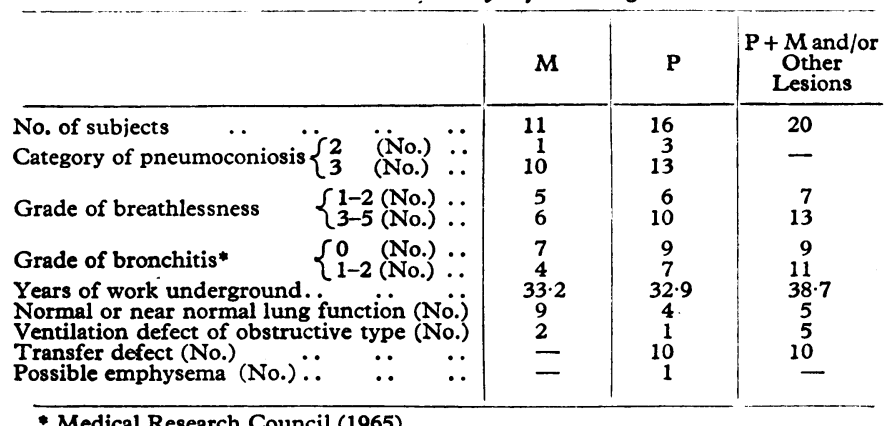

- Medical Research Council (1965)

$\mathrm{M}=$ Pure micronodular type. $\mathrm{P}=$ Pure pin-head type.

TABLE II.-Findings on Assessment of Lung Function (Mean Values)

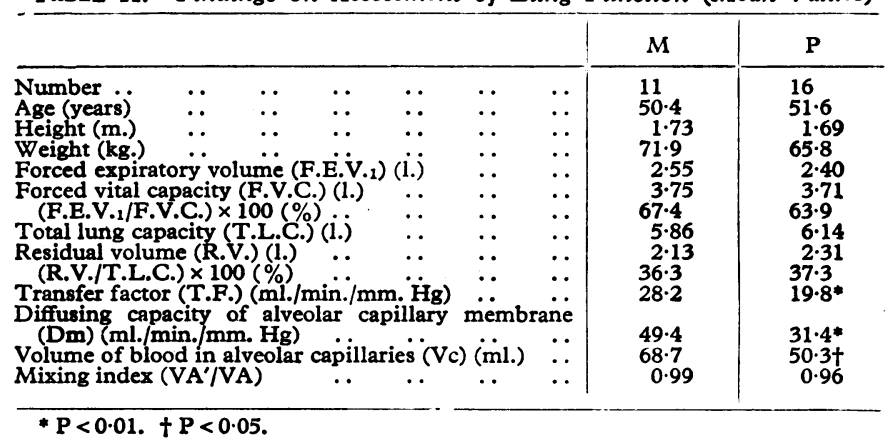

This shows that the mean transfer factor for the men with the pin-head opacities is significantly less than that for the men with the micronodular opacities. The other findings are within the normal range.

In view of this result the $x$-ray films were re-read by W. G. C., who at no time had knowledge of the lung function findings. His readings differed from those on the first occasion only to the extent that two of the men initially graded as pure pin-head were now thought to have mixed pin-head and micronodular opacities. In both of these men the transfer factor was near to the average for their age and height. In addition the data were examined with respect to smoking habits, when it was found that the proportion of smokers among the men with the pin-head opacities $(13 / 16)$ was higher than among those with the micronodular opacities $(3 / 11)$. The smokers had lower values for the transfer factor than the non-smokers and exsmokers (mean difference associated with smoking $6.2 \mathrm{ml} . / \mathrm{min}$./ $\mathrm{mm}$. Hg, $\mathrm{P}<0.05$ ). However, the transfer factors for both the smokers and the non-smokers and ex-smokers were, on average, lower in the men with the pin-head opacities than in those with the micronodular opacities; the overall difference after adjusting for smoking was $5.4 \mathrm{ml} . / \mathrm{min} . / \mathrm{mm}$. $\mathrm{Hg}(P \simeq 0.07)$.

\section{Discussion}

The subjects for this study differ from the general population of coal miners in that they were referred after attendance at the Pneumoconiosis Medical Panel. The group may therefore be biased in two ways: (1) with respect to men having respiratory symptoms, because such men may be more likely to attend on their own initiative than men without symptoms; and (2) with respect to the extent of the radiological abnormality, because men with dense or progressive lesions are likely to be recalled to the Panel at more frequent intervals than those with less pronounced pneumoconiosis. However, that the former selective process was operating to a comparable extent for the men with both pin-head and micronodular opacities is suggested by the similarity of their average grades for both breathlessness and bronchitis (Table I). Therefore the finding for the transfer factor of a lower average value in the pin-head cases is unlikely to be biased on this account.

The cause for the low transfer factor is not known; it may be related to the dust in the lung or the reaction of the lung tissue. For example, it may be a result of more dust being present in the lung with the pin-head lesions than in one where the micronodular lesions predominate. Evidence on this aspect is so far incomplete (Rossiter et al., 1967), but it is relevant that the average periods of work underground (Table I) and of work on the coal face do not differ to a material extent between the two groups of men. The nature of the reaction in the lung tissue in the pin-head cases is also unknown. The radiological appearance on a good-quality $x$-ray film is often an overall obscuration of the lung markings and of the "black" air spaces by the minute opacities, particularly at the lung bases. In addition there may be some linear opacities. These findings are suggestive of changes in the lung parenchyma, but the number of cases that were classified by their type of pneumoconiosis during life and have since come to necropsy is not yet large enough for a conclusion to be reached on this point.

Any morphological differences which may exist are unlikely to be related to diffuse infiltration of the rheumatoid type, since the serum titres for aggregated human gammaglobulin show little difference between the pin-head and the micronodular cases. In addition, the rate of progression to massive fibrosis, which may be dependent on this process (Wagner and McCormick, 1967), is if anything less for the pinhead cases. These points need to be clarified by a longitudinal study. In addition the apparent absence of a relation between the low transfer factor and breathlessness or other symptom requires examination by study of both these subjects in more detail, and other subjects selected by a process of random sampling from among men with simple pneumoconiosis.

\section{Summary}

Among men attending a pneumoconiosis medical panel a gas transfer defect of the lungs was observed in 10 out of 16 with simple pneumoconiosis whose opacities were of a pure pin-head type, but in none of 11 men whose opacities were of the micronodular type.

We are indebted to Dr. J. Watkins-Pitchford, Chief Medical Officer, Ministry of Social Security, and to members of the 
Pneumoconiosis Medical Panel, Cardiff, for referral of cases; to Messrs. F. U. Oldham and G. Berry for statistical advice; and to Miss E. Dawkins for technical assistance.

\section{REPERENCES}

Brasseur, L. (1963). L'exploration fonctionnelle pulmonaire dans la pneumoconiose des houilleurs. Brussels.

Cotes, J. E. (1965). Lung Function. Oxford.

Englert, M., and De Coster, A. (1965). F. franç. Méd. Chir. thor., 19, 159.

Gaensler, E. A., Hoffman, L., and Elliott, M. F. (1960). Poumon, 16,
International Labour Office (1959). Occupational Safety and Health, 9. - (1966). Occupational Safety and Health Series, No. 6. Geneva.

Meade, F., Saunders, M. J., Hyett, F., Reynolds, J. A., Pearl, N., and Cotes, J. E. (1965). Lancet, 2, 573 .

Medical Research Council (1960), Brit. med. 7., 2, 1665

Nica (1965). Lancet, 1, 775 .

Nicaise, R., Vereerstraten, J., and de Clercq, F. (1967). Proc. roy. Ned. Tuberc. Ass., Selocted Papers, 10, 70.

Podlesch, I., Stevanowic, M., and Ulmer, W. T. (1966). Med. thorac. (Basel), 23, 283.

Rossiter, C. E., Rivers, D., Bergman, I., Casswell, C., and Nagelschmidt, G. (1967). Inhuled Particles and Vapours, vol., 2 , edited by C. N. Davies, p. 419. Oxford.

Wagner, J. C., and McCormick, J. N. (1967). F. roy. Coll. Phycns, 2, 49.

\title{
Outbreak of E.C.H.O. Virus Type 30 in a General Practice
}

\author{
D. H. IRVINE,* M.D. ; A. B. H. IRVINE,* M.B., CH.B. ; P. S. GARDNER, † M.D., DIP.BACT.
}

Brit. med. F., 1967, 4, 774-776

For many years E.C.H.O. viruses have been known aetiological agents in human disease, particularly aseptic meningitis; examples include type 4 (Chin et al., 1957), type 6 (Kibrick et al., 1957), and type 9 (Tyrrell and Snell, 1956). One of the latest to be linked with aseptic meningitis is type 30, described in Scotland originally as the "Frater virus" (Duncan, 1960). A virus now known to be identical was described in the United States as the "Bastianni virus" (Plager and Decher, 1963).

E.C.H.O. virus type 30 was first incriminated in illness in this country in 1950-60 and has been encountered only occasionally between 1960 and 1964 (Grist and Bell, 1967). Current information on symptomatology is based on isolated cases seen in hospital practice. In this communication we describe an outbreak of a febrile illness observed in a general practice for which there is evidence that the causal agent may have been E.C.H.O. virus type 30 .

\section{Present Investigation}

The practice has two principals and a list of approximately 5,140 patients. Though the majority of patients are resident in Ashington, a colliery town with a population of 28,000 people, a considerable number live either in the adjacent urban

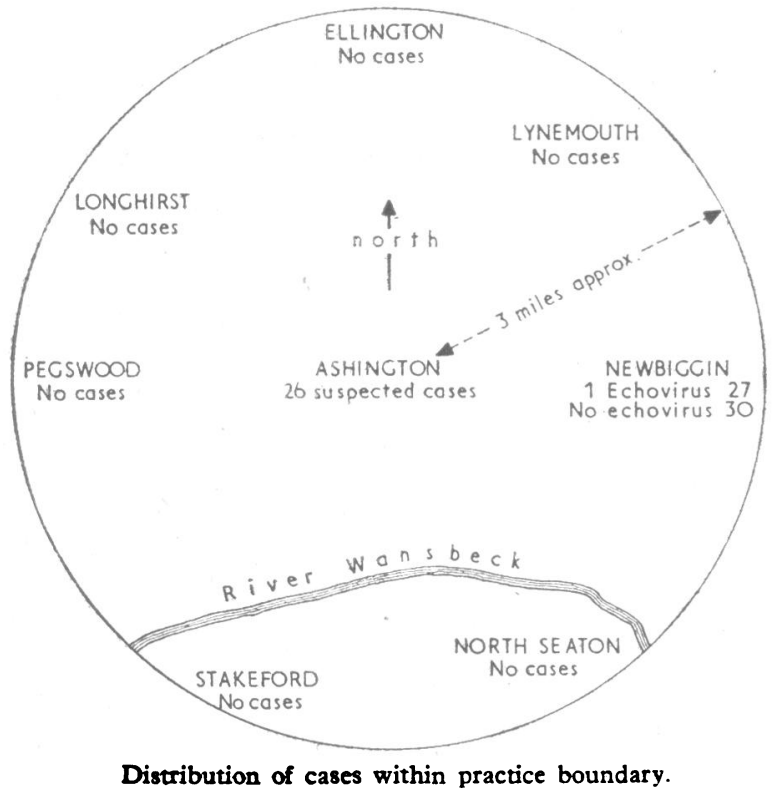

Distribution of cases within practice boundary area of Stakeford, which lies on the opposite bank of the River Wansbeck, or in one of five near-by villages. The practice boundary is within a 3 -mile $(5-\mathrm{km}$.) radius from the centre of Ashington (see Fig.).

The outbreak began in mid-June 1966, when two children presented within a day or two of each other a clinical picture suggestive of aseptic meningitis. Faeces were sent for laboratory examination, but before the results became available two further cases were seen, though the illness was less severe. As it was now evident that an unusual illness was prevalent in the practice, arrangements were made to widen the field of study. It was agreed to observe any new patients presenting with a febrile complaint in whom it was impossible initially to make a definite diagnosis or who had symptoms similar to those seen in the earlier cases. This system of screening was thought desirable since no pathogen had been identified at that stage. It was anticipated that in some cases an alternative diagnosis would emerge ; in the event these cases, with one exception, were grouped together before individual laboratory results became available (group C below).

Laboratory Methods.-Specimens of stool were taken from all suspected cases. On arrival in the laboratory these specimens were emulsified in a $10 \%$ suspension and centrifuged. Then 0.2 and $0.1 \mathrm{ml}$. respectively were inoculated into two monkeykidney and two Hep. 2 tissue culture tubes. Tissue culture tubes were examined daily; suspected virus agents were passaged into fresh tubes and identified by neutralization against specific antisera. Details of the laboratory procedures used have been described (Gardner et al., 1961; Gardner and Cooper, 1964).

\section{Results}

Altogether 46 patients were examined in the period from 10 June to 22 August. It has been found convenient to classify them into three groups as follows:

Group A: Twenty-two patients (9 female, 13 male) with a symptom pattern peculiar to the outbreak in whom E.C.H.O. virus 30 was isolated from faeces.

Group $B$ : Four patients (all female) with similar clinical features as group $A$ in whom no virus was found in faeces.

Group C: Twenty patients ( 7 female, 13 male) presenting with a febrile malaise and later shown to be suffering from another condition. E.C.H.O. virus type $\mathbf{3 0}$ was not identified in their faeces.

* General Practitioner, Ashington, Northumberland.

t Consultant Virologist, Royal Victoria Infirmary and University of Newcastle upon Tyne. 